\title{
Two Cases of Left-Sided Tricuspid Atresia with Situs Solitus L-Bulboventricular Loop and L-Transposition of the Great Arteries
}

\author{
Tetsuo Sato, Ichiki Kano, Mortkuni Fukuda, Yoshiro \\ Yoshida, Takashi Sasaki and Hrsao Hoshino \\ Department of Pediatrics, Tohoku University School of Medicine, \\ Sendai
}

\begin{abstract}
Sato, T., Kano, I., Fukuda, M. Yoshida, Y., Sasaki, T. and Hoshino, H. Two Cases of Left-Sided Tricuspid Atresia with Situs Solitus, L-Bulboventricular Loop and L-Transposition of the Great Arteries. Tohoku J. exp. Med., 1976, 119 (4), 385-392 — Two cases of extremely rare type of tricuspid atresia are presented. Both possessed left-sided tricuspid atresia, situs solitus of viscera and atria, 1-bulboventricular loop and 1-transposition of the great arteries. These anomalies are typical tricuspid atresia with 1-transpositions. The importance of bulboventricular loop in tricuspid atresia is emphasized because the atretic tricuspid valve is right-sided in the heart with solitus and d-loop, and is left-sided in the heart with solitus and 1-loop. ___ loop; transposition; malposition
\end{abstract}

Tricuspid atresia is a congenital anomaly in which the atrioventricular valve of the morphologic right ventricle is atretic, because the tricuspid valve would be embryologically connected to the morphologic right ventricle. As a result, atretic atrioventricular valve is usually right-sided in this anomaly, but is rarely left-sided. In the heart with situs solitus and d-bulboventricular loop, the tricuspid valve is right-sided since the right atrium drains to the right-sided, morphologic right ventricle (concordant atrioventricular relationships). On the contrary, in the heart with situs solitus and 1-bulboventricular loop, the tricuspid valve is left-sided since the left atrium drains to the left-sided, morphologic right ventricle (discordant atrioventricular relationships).

To our knowledge, only three cases of left-sided tricuspid atresia as mentioned above have been reported without detailed descriptions (Paul 1968; Tandon et al. 1974). These cases are tricuspid atresia with 1-transpositions in the accurate definitions (Van Praagh et al. 1971; Kirkline et al. 1973).

This paper presents two cases of left-sided tricuspid atresia with solitus, 1loop and 1-transpositions. Both were diagnosed by angiocardiography and one of them was confirmed at autopsy and the other by palliative surgery.

Received for publication, March 18, 1976. 


\section{Case Report}

Case 1 .

A 4-month-old girl was admitted to our hospital because of cyanosis and failure to thrive. She was born uneventfully at term, weighing $3,040 \mathrm{~g}$. Cyanosis and failure to thrive were first noted at one month of age.

On admission, physical examinations revealed a poorly nourished, tachypneic and irritable girl, weighing $5,100 \mathrm{~g}$. There was marked cyanosis on lips and nail beds. Breath sounds were clear. Systolic murmurs of grade $2 / 6$ were audible at the pulmonic area. The second sounds were accentuated but not split. The liver was felt $3 \mathrm{~cm}$ below the right costal margin. Chest $\mathrm{x}$-ray film showed cardiac enlargement, wide supracardiac shadow with gradually sloping left border and marked increase in pulmonary vascularity. Electrocardiograms showed regular sinus rhythm, right axis deviation, tall $P$ waves in II, III, aVF leads and absent $Q$ waves in $\mathrm{I}$, left precordial leads and present $\mathrm{Q}$ waves in III, aVF, right precordial leads (Fig. 1A). These findings suggested the presence of ventricular inversion (Ruttenberg et al. 1966).

The result of cardiac catheterization is presented in Table 1. Left-to-right shunt was demonstrated at the atrial level. The oxygen saturation of the blood was identical at the right atrium, both ventricles and both great arteries. Pressure recordings revealed severe pulmonary hypertension and elevated pressure at the pulmonary arterial wedge. The pulmonary to systemic arterial systolic pressure ratio $\left(\mathrm{P}_{\mathrm{p}} / \mathrm{P}_{\mathrm{s}}\right)$ was 1.0 and the pulmonary to systemic arterial blood flow ratio $\left(\mathrm{Q}_{\mathrm{p}} / \mathrm{Q}_{\mathrm{s}}\right)$ was 0.48. Angiocardiograms with injection of the contrast material into one of the ventricles revealed right-sided, morphologic left ventricle, from which the pulmonary artery originated posteriorly and rightward and left-sided morphologic right ventricle, from which the aorta originated anteriorly and leftward. The

A

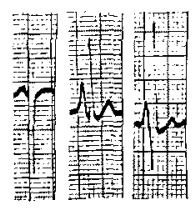

I II $\mathbb{I I}$

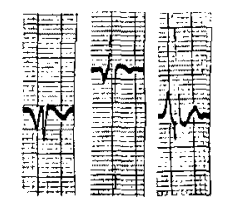

$O V_{\mathrm{A}} \quad O V_{L} \quad O V_{F}$
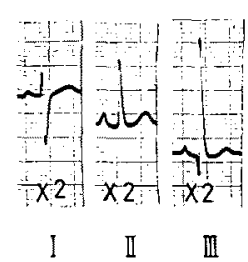

$\mathrm{B}$

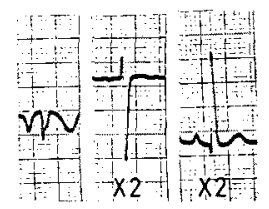

$\begin{array}{lll}O V_{R} & O V_{L} & O V_{F}\end{array}$
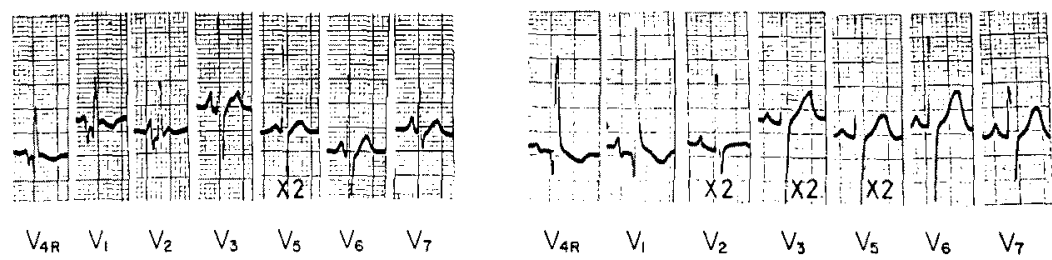

Fig. 1. Electrocardiograms of Case $1(A)$ and Case $2(B)$. Note absence of $Q$ wave in $I$ and left precordial leads and presence of $Q$ waves in III, aVF and right precordial leads, suggesting ventricular inversion. 
TABLE 1. Cardiac catheterization data

\begin{tabular}{|c|c|c|c|c|c|c|}
\hline & \multicolumn{3}{|c|}{ Case 1} & \multicolumn{3}{|c|}{ Case 2} \\
\hline & \multicolumn{2}{|c|}{ Pressure $(\mathrm{mmHg})$} & \multirow{2}{*}{$\begin{array}{c}\text { Oxygen } \\
\text { saturation } \\
(\%)\end{array}$} & \multicolumn{2}{|c|}{ Pressure $(\mathrm{mmHg})$} & \multirow{2}{*}{$\begin{array}{c}\text { Oxygen } \\
\text { saturation } \\
(\%)\end{array}$} \\
\hline & $\begin{array}{l}\text { Systole/ } \\
\text { Diastole }\end{array}$ & Mean & & $\begin{array}{l}\text { Systole/ } \\
\text { Diastole }\end{array}$ & Mean & \\
\hline Superior vena cava & - & - & 47 & - & - & 60 \\
\hline Inferior vena cava & - & - & 48 & - & - & 73 \\
\hline Right atrium & - & 8 & 65 & - & 7 & 86 \\
\hline Left ventricle & $76 / 6$ & 一 & 65 & $90 / 8$ & - & 91 \\
\hline Right ventricle & $76 / 6$ & - & 64 & $88 / 8$ & - & 88 \\
\hline Aorta & $72 / 40$ & 58 & 63 & $84 / 40$ & 55 & 87 \\
\hline Pulmonary artery & $72 / 32$ & 52 & 64 & $56 / 20$ & 40 & 90 \\
\hline Left atrium & - & - & 95 & - & 20 & 97 \\
\hline $\begin{array}{l}\text { Pulmonary arterial } \\
\text { wedge }\end{array}$ & 一 & 28 & - & - & 20 & - \\
\hline
\end{tabular}

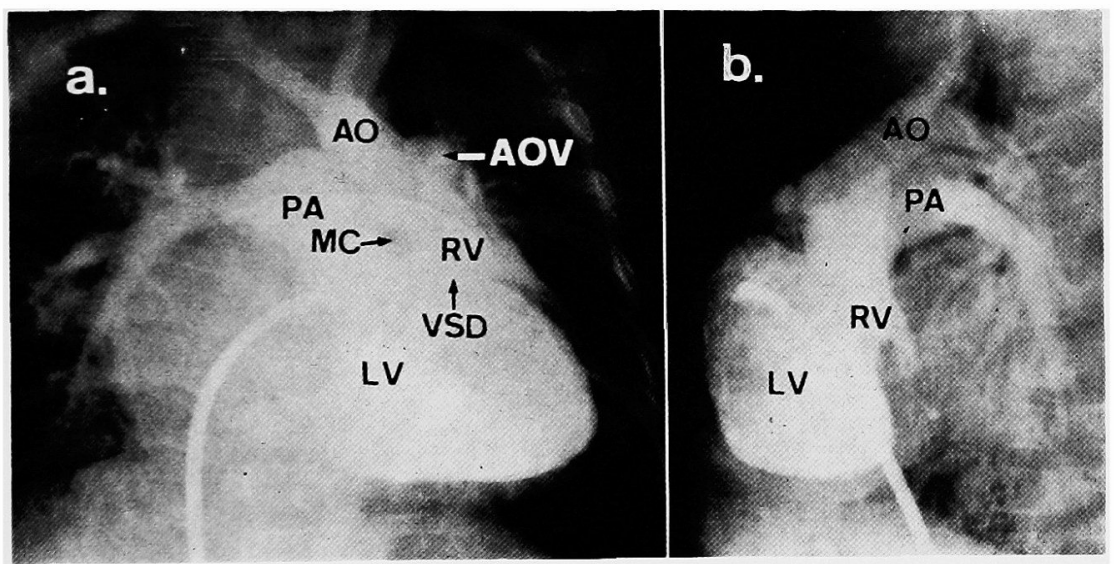

Fig. 2. Angiocardiograms, Case 1.

a: Frontal projection with the contrast material injected into the morphologic left ventricle $(L V) . \quad L V$ is right-sided and receives systemic venous blood from the right atrium through the mitral valve. The pulmonary artery originates from $L V$. The morphologic right ventricle $(\mathrm{RV})$ is left-sided and markedly hypoplastic. The aorta (AO) originates from $\mathrm{RV}$ to the left of PA. Note a muscular conus (MC) beneath the aortic valve $(\mathrm{AOV})$ and a ventricular septal defect (VSD).

b: Lateral projection with the same injection. Note anterior AO, posterior PA, large $\mathrm{LV}$ and hypoplastic RV.

morphologic right ventricle was markedly hypoplastic and had a muscular conus beneath the aortic valve (Fig. 2).

She died in acute respiratory distress 4 months later. Postmortem examinations showed the followings: The situs of viscera and atria was solitus. The right atrium received the superior and inferior venae cavae and coronary sinus in a normal manner. The foramen ovale was patent. The right atrium drained to the right-sided, morphologic left ventricle by way of an orifice characteristic of a 

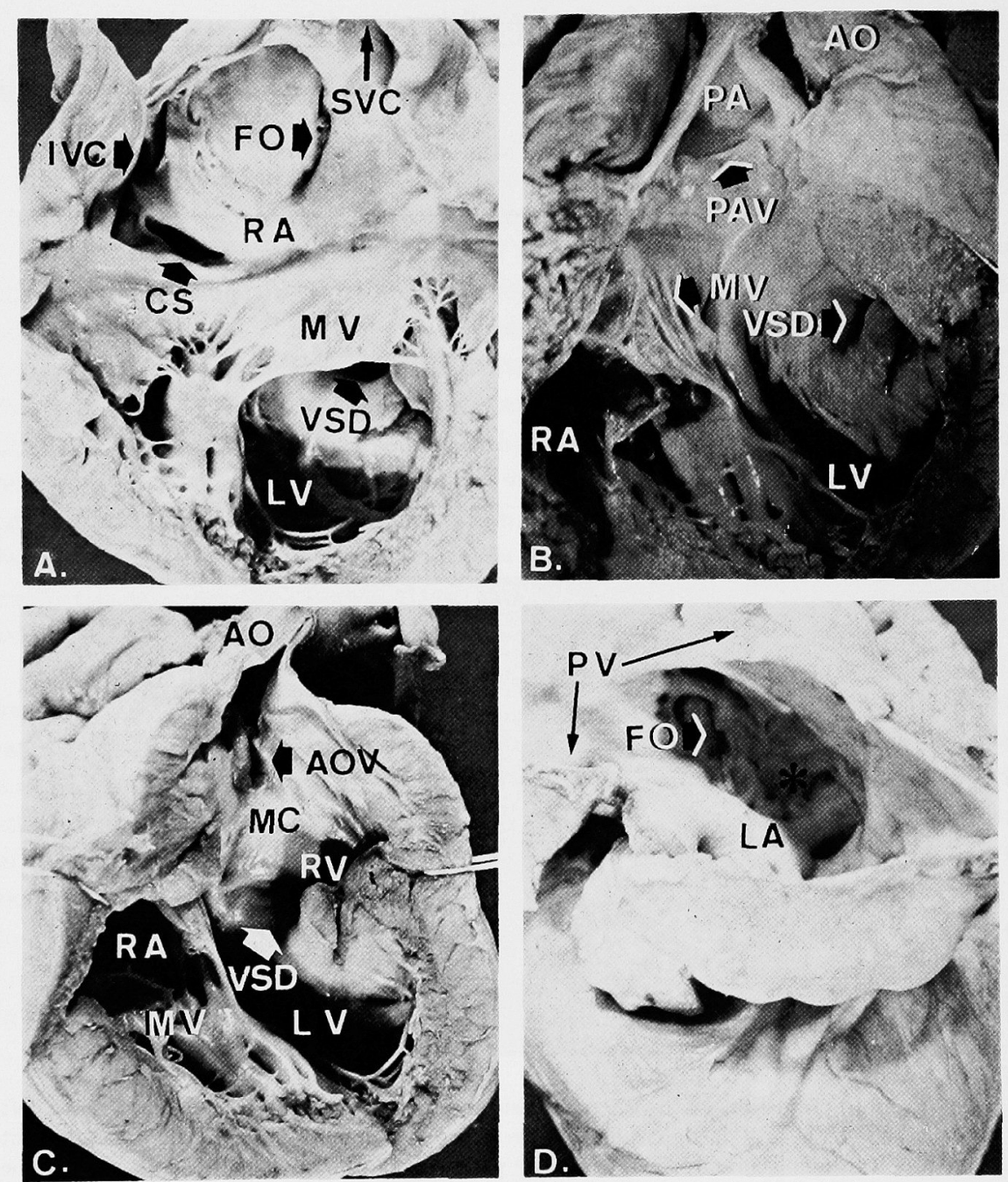

Fig. 3. Heart specimen, Case 1.

A: The opened morphologic right atrium (RA) and left ventricle (LV). RA receives the superior vena cava (SVC), inferior vena cava (IVC) and coronary sinus (CS), and drains into $\mathrm{LV}$ through the mitral valve (MV). Note patent foramen ovale (FO) and ventricular septal defect (VSD).

$\mathrm{B}$ : The opened $\mathrm{LV}$, viewed through subpulmonary incision. The pulmonary artery (PA) originates from $L V$ to the right of the aorta $(\mathrm{AO})$. A fibrous continuity is present between the pulmonary valve (PAV) and MV.

C: The opened morphologic right ventricle (RV), view through subaortic incision. $R V$ is markedly hypoplastic and its inlet is only VSD. A subaortic muscular conus (MC) prevents a fibrous continuity between the aortic valve (AOV) and the atrioventricular valve.

D: The opened morphologic left atrium (LA). LA receives all pulmonary veins (PV) and the outlet of LA is only FO since the left-sided atrioventricular valve (tricuspid valve) is atretic $\left(^{*}\right)$. 
mitral valve (Fig. 3A). The pulmonary artery originated from the morphologic left ventricle posteriorly and to the right of the aorta. A fibrous continuity was present between the pulmonary valve and the mitral valve (Fig. 3B). The leftsided, morphologic right ventricle was markedly hypoplastic and its inlet was only the ventricular septal defect. The aorta originated from the morphologic right ventricle anteriorly and to the left of the pulmonary artery. A subaortic muscular conus prevented a fibrous continuity between the aortic valve and the atrioventricular valve (Fig. 3C). The left atrium received all pulmonary veins. The left-sided atrioventricular valve (tricuspid valve) was atretic and the outlet of the left atrium was only the foramen ovale (Fig. 3D). The coronary arterial pattern was characteristic of ventricular inversion (Elliott et al. 1966). The anterior descending branch arose from the proximal right coronary artery.

\section{Case 2.}

A 19-month-old boy was admitted to our hospital because of cyanosis, cardiac murmurs and failure to thrive. He was delivered uneventfully at term after normal pregnancy, weighing $3,600 \mathrm{~g}$. The cardiac murmurs and cyanosis were first noted 2 months after birth.

On admission, physical examinations revealed a poorly nourished, tachypneic boy, weighing $10 \mathrm{~kg}$. There was moderate cyanosis on lips and nail beds. Breath sounds were clear. Systolic murmurs of grade $4 / 6$ and diastolic murmurs of grade $2 / 6$ were audible at the left lower sternal border. The second sounds were accentuated and split. The liver was felt $3 \mathrm{~cm}$ below the right costal margin. The findings of the chest $\mathrm{X}$-ray film and the electrocardiograms (Fig. 1B) were similar to those of Case 1. The result of cardiac catheterization is presented in Table 1. It was also similar to that of Case 1. The findings of the angiocardiogram with injection of the contrast material into the ventricle were identical to those of Case 1 (Fig. 4A). An angiocardiogram with injection into the left atrium revealed the atresia of the left-sided atrioventricular valve (tricuspid valve) and an atrial septal defect, through which the contrast material passed from the left atrium to the right atrium (Fig. 4B).

Because of intractable congestive heart failure, surgical creation of atrial septal defect and banding of the pulmonary arterial trunk were carried out with an uneventfull postoperative course. At the time of these surgical procedures, the coronary arterial pattern was found to be characteristic of ventricular inversion. The anterior descending branch arose from the proximal right coronary artery.

\section{DISCUSSION}

Our two cases have tricuspid atresia with situs solitus of viscera and atria, 1bulboventricular loop and 1-transposition of the great arteries (physiologically corrected transposition). In each case, the left-sided tricuspid valve is atretic (Fig. 5D). The morphologic left ventricle is right-sided and receives venous blood from the right atrium through the mitral valve. The morphologic right ventricle 


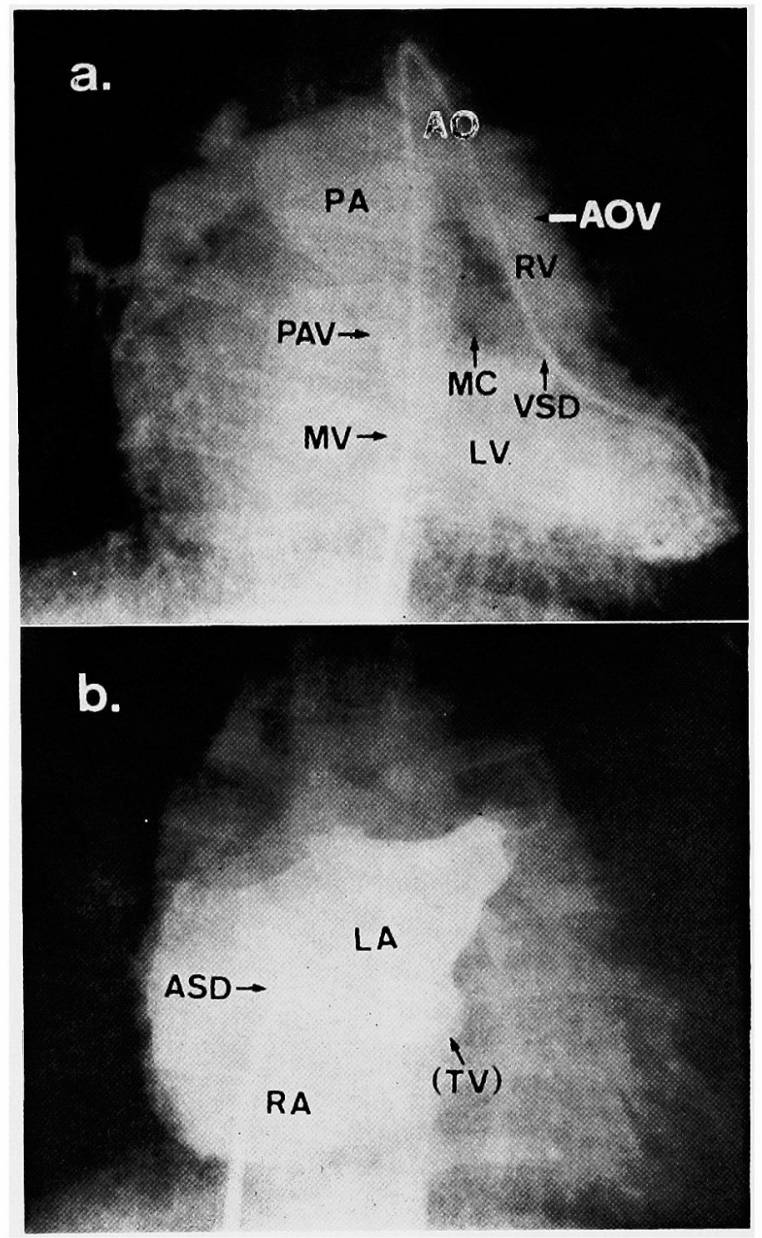

Fig. 4. Angiocardiograms, Case 2.

a: Frontal projection with the contrast material injected into the morphologic left ventricle $(\mathbf{L V}) . \quad \mathbf{L V}$ is right-sided and receives systemic venous blood from the right atrium through the mitral valve (MV). The pulmonary artery (PA) originates from LV. The morphologic right ventricle (RV) is left-sided and markedly hypoplastic and has a muscular conus (MC) beneath the aortic valve (AOV). The aorta (AO) originates from $\mathrm{RV}$ to the left of $\mathrm{PA}$. $\mathrm{AOV}$ is superior to and to the left of the pulmonary valve (APV). $\mathrm{LV}$ and $\mathrm{RV}$ communicates through a ventricular septal defect (VSD).

b: Frontal projection with the contrast material into the left atrium (LA). The leftsided atrioventricular valve, namely tricuspid valve (TV) is atratic. The outlet of LA is only an atrial septal defect (ASD). The inlet of RV is only VSD.

is left-sided and markedly hypoplastic. The outlet of the left atrium receiving all pulmonary veins is only the atrial septal defect because of the atretic atrioventricular valve. The inlet of the morphologic right ventricle is only the ventricular septal defect. The aorta originates from the morphologic right ventricle 

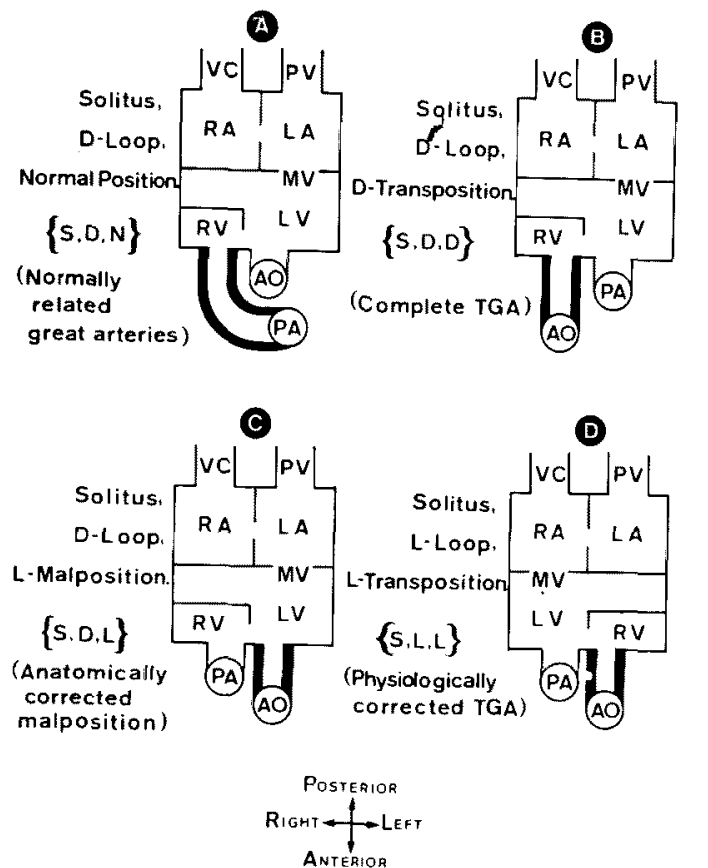

Fig. 5. Diagrams of tricuspid atresia with or without transposition. Atretic tricuspid valve is right-sided in the heart with situs solitus, $d$-bulboventricular loop $(A, B, C)$ or left-sided in the heart with situs solitus, 1-bulboventricular loop (D).

Abbreviations: AO, aorta; $L A$, left atrium; $L V$, left ventricle; MV, mitral valve; PA, pulmonary artery; $P V$, pulmonary vein; $R A$, right atrium; $R V$, right ventricle; $V C$, vena cava.

anteriorly and to the left of the pulmonary artery. The pulmonary artery originates from the morphologic left ventricle posteriorly and to the right of the aorta.

The tricuspid valve is embryologically right-sided in the heart with situs solitus and d-loop (concordant atrioventricular relationships) or left-sided in the heart with situs solitus and 1-loop (discordant atrioventricular relationships). As a result, atresia of the tricuspid valve is right-sided in the heart with solitus and $d$ loop (Figs. 5A, B, C) or left-sided in the heart with solitus and 1-loop (Fig. 5D). The former is usual but the latter is extremely rare (Paul 1968; Tandon et al. 1974).

An anatomic classification of tricuspid atresia was proposed by Edwards and Burchell (1949). It included the recognition of two types of tricuspid atresia; namely, without transposition of the great arteries (type I) and with transposition of the great arteries (type II). Keith and co-workers (1967) modified the classification to include 1-transposition and referred this form to type III and restricted d-transposition to type II. They described 4 cases of tricuspid atresia with 1-transposition. However, their 3 cases were right-sided tricuspid atresia with solitus, d-loop and l-malposition, namely anatomically corrected malposition (Kirkline et al. 1973) in which the pulmonary artery arose from the right-sided, 
morphologic right ventricle and tha aorta arose from the left-sided, morphologic left ventricle anteriorly and to the left of the pulmonary artery (Fig. 5C). The other case was in fact right-sided mitral atresia with solitus, 1-loop and 1transposition, and therefore the patent atrioventricular valve was a left-sided tricuspid valve (Keith et al. 1967).

Paul (1968) found 2 cases of left-sided tricuspid atresia in 21 hearts with solitus, l-loop and l-transposition of the great arteries. Tandon and co-workers (1974) described 5 cases of tricuspid atresia with l-transposition. As in our cases, one of them was indeed left-sided tricuspid atresia with solitus, 1-loop and l-transposition. However, their other 4 cases were right-sided tricuspid atresia with solitus, d-loop and l-malposition.

Tricuspid atresia with l-malposition should be distinctly differentiated from that with l-transposition, becuase the atretic valve is right-sided in the former but is left-sided in the latter. It is also of clinical importance whether the atretic tricuspid valve is right-sided or left-sided, since the former can be surgically corrected (Fontan and Baudet 1971; Kreutzer et al. 1973) but the latter can not be corrected at present. Moreover, the latter presents clinical features indentical to those of mitral atresia and, therefore, is more difficult to diagnose correctly than the former.

\section{References}

1) Edwards, J.E. \& Burchell, H.B. (1949) Congenital tricuspid atresia. A classification. Med. Clin. N. Amer., 33, 1177-1196.

2) Elliott, L.P., Amplatz, K. \& Edwards, J.E. (1966) Coronary arterial patterns in transposition complexes. Anatomic and angiocardiographic studies. Amer, $J$. Cardiol., 17, $362-378$.

3) Fontan, F. \& Baudet, E. (1971) Surgical repair of tricuspid atresia. Thorax, 26, 240248.

4) Keith, J.D., Rowe, R.D. \& Vlad, P. (1967) Tricuspid atresia. In: Heart Disease in Infancy and Childhood. 2nd ed., edited by J.E. Keith, R.D. Rowe \& P. Vlad, Macmillan Publishing Co., Inc., New York, pp. 644-681.

5) Kirkline, J.W., Pacifico, A.D., Bargeron, L.M. \& Soto, B. (1973) Cardiac repair in anatomically corrected malposition of the great arteries. Circulation, 48, 153-159.

6) Kreutzer, G., Galindez, E., Bone, H., de Palma, C. \& Laura, J.P. (1973) An operation for the correction of tricuspid atresia, J. Thorac. cardiovasc. Surg, 66, 613-621.

7) Paul, M.H. (1968) Tricuspid atresia. In: Pediatric Cardiology, edited by H. Watson, Loyd-Luke, Ltd., London, pp. 451-467.

8) Ruttenberg, H.D.. Elliott, L.P., Anderson, R.C., Adams, P. \& Tuna, P. (1966) Congenital corrected transposition of the great arteries. Correlation of electrocardiograms and vectorcardiograms with associated cardiac malformations and hemodynamic states. Amer. J. Cardiol., 17, 339-354.

9) Tandon, R., Marin-Garcia, J., Moller, J.H. \& Edwards, J.E. (1974) Tricuspid atresia with 1-transposition. Amer. Heart J., 88, 417-424.

10) Van Praagh, R, Pérez-Trevino, C., Lopez-Cuellar, M., Baker, F.W., Zuberbuhler, J.R., Pérez, V.R., Quero, M., Moreno, F. \& Van Praagh, . (1971) Transposition of the great arteries with posterior aorta, anterior pulmonary artery, subpulmonary conus and fibrous continuity between aortic and atrioventricular valves. Amer. $J$. Cardiol., 28, 621-631. 